Article

\title{
Improvement of the Welding Process for Fillet Air Test for the Biggest Taiwan Shipyard
}

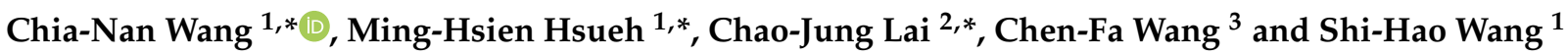 \\ 1 Department of Industrial Engineering and Management, National Kaohsiung University of Science \\ and Technology, Kaohsiung 807, Taiwan; shwang@nkust.edu.tw \\ 2 Department of International Business, National Kaohsiung University of Science and Technology, \\ Kaohsiung 807, Taiwan \\ 3 China Ship Building Corporation, Kaohsiung 812, Taiwan; 082246@csbcnet.com.tw \\ * Correspondence: cn.wang@nkust.edu.tw (C.-N.W.); mhhsueh@nkust.edu.tw (M.-H.H.); \\ I107159104@nkust.edu.tw (C.-J.L.)
}

Citation: Wang, C.-N.; Hsueh, M.-H.; Lai, C.-J.; Wang, C.-F.; Wang, S.-H. Improvement of the Welding Process for Fillet Air Test for the Biggest Taiwan Shipyard. J. Mar. Sci. Eng. 2021, 9, 80. https://doi.org/ 10.3390/jmse 9010080

Received: 22 December 2020 Accepted: 8 January 2021 Published: 13 January 2021

Publisher's Note: MDPI stays neutral with regard to jurisdictional clai$\mathrm{ms}$ in published maps and institutional affiliations.

Copyright: $\odot 2021$ by the authors. Licensee MDPI, Basel, Switzerland. This article is an open access article distributed under the terms and conditions of the Creative Commons Attribution (CC BY) license (https:// creativecommons.org/licenses/by/ $4.0 /)$.

\begin{abstract}
During ship block construction, watertight bulkheads weld of every cabin of ships need to undergo stress testing according to the tanks' test plan. Every incomplete bulkhead cannot be sprayed in order to protect them after sandblasting; this seriously affects the process of construction. Therefore, the issue of this study is to maintain the integrity of the painting quality and reduce the destruction of the paint, ship-building personnel seek how best to complete the block operation. The aim of this project is to improve the recent watertight bulkheads fillet air test operations in the construction stage using TRIZ (theory of inventive problem solving), promote the ground painting session integrity of every ship, improve the tanks' test plan in the dock, and reduce the time spent on dismantling operations and the painting operation. Through the TRIZ, this study proposed lots of improvements, some of which are: the watertight cabins can finish the tanks test plan completely, and the integrity of the ground painting can be promoted to reduce the range of cabin test in the dock and reduce watertight bulkheads' dismantling time. Moreover, because of the considerate reduction of the destruction of the coating, the painting operation is of good quality. The results demonstrate that the TRIZ successfully controls the production quality during construction, reduces working time, and promotes full efficiency. This study saved more than US $\$ 1$ million of the outsourcing fee.
\end{abstract}

Keywords: shipbuilding; fillet air test; welding; TRIZ

\section{Introduction}

Notwithstanding the unclear expectations about global economic resurgence in 2020, the shipping market still possessed high transport capacity. Additionally, between 2017 and 2020, all of the orders for ultra large container ships above 10,000 TEU were delivered successively. However, the container ship freight rate levels need to be subjected to strict tests [1]. Therefore, there remains a severe imbalance in the supply and demand of new ships; even as new orders continue to decrease globally. As the supply exceeds demand in the shipping market, new ship prices will be lowered continuously [2].

The economy had experienced a decline since 2010, therefore, orders were drastically reduced, and even cancelled. As a result, the shipbuilding market supply exceeds demand and the ship price has dropped to about $70 \%$ of what it was during the economic boom. Clearly, this has severely impacted the profit margin of dockyards. In response to this economic decline, large merchant ship builders in Taiwan actively initiated management reforms by using information systems to enhance the management's design and production abilities. These reforms also encourage proposals for improvements and cost reduction in modification processes and equipment enhancement, so as to increase their profit margins [3]. This study is developed against this background. 
The Yearbook of Ship and Ocean Industries R\&D Center [4] indicates that the development of the ship manufacturing industry in Taiwan is approximately divided into one large ship builder, five intermediate ship builders, 75 small ship builders, 35 yacht plants, and 10 ship part plants. The ship manufacturing industry of Taiwan makes numerous elites from the shipbuilding circles take an active part in the Asia Pacific shipping system, so that the shipbuilding industry of Taiwan creates the fine quality word-of-mouth of Made in Taiwan in global shipping interests [5]. In view of this, this study samples the process improvement of a shipbuilder in Taiwan for its case study, with the hope that the research findings can provide references for related industries.

The shipbuilding industry has a huge production system involved in cutting, subassembly, block combination, painting, grand assembly, and assembling of a ship since millions of plates are required to be assembled. The manufacturing process uses the block production mode, so as to assemble the outfits and system pipe fittings and to perform block painting [6]. The production efficiency directly influences the time spent on shipbuilding, product quality, and construction cost [7]. It then becomes important to understand how to optimize the block construction sequence, shorten the shipbuilding period, and improve the quality of the products.

This study uses TRIZ in the BLOCK manufacturing stage to creatively improve the pressure test operation for watertight bulkhead, so as to increase the efficiency of the downstream operation flow.

\section{Literature Review}

The shipbuilding industry is an international manufacturing industry, therefore, the construction process must conform to the regulations established by various regulatory bodies. The classification societies, which the shipbuilding circles of Taiwan often contact, are: ABS American Bureau of Shipping, DNV Det Norske Veritas, LR Lloyd's Register, NK Nippon Kaiji Kyokai (Class NK), BV Bureau Veritas, and China Corporation Register of Shipping. Importantly, the regulation contents of global shipbuilding circles are slightly different, especially in relation to the required data content [8].

The compartment watertight wall pressure test method and air pressure test specification for new ships are fundamental shipbuilding regulations. Therefore, the special primer is the practice before improvement. When the block is sandblasted, the compartment bead before the pressure test is coated with the classification society-approved precoating prime to prevent corrosion. When the pressure test is finished, the bead is derusted and painted again [9]. The hydrostatic test operation for the newly built ships is usually difficult to be replaced. Thus, in the shipbuilding circles, when the compartment is finished, the whole compartment is filled up with water for the test for air pressure test; this replaces the vacuum test and fillet weld pressure test.

Lots of scholars have even put attention in fillet welding in ship making. Azad et al. [10] presented a study that the effect of welding sequences on the magnitude and shape of distortion in the ship deck structure. The effects of eight welding sequences on the magnitude and shape of distortion in the plate on six lines were investigated. The significant features of occurred distortion for various welding sequences in which not only the magnitudes but also the deformed shapes of the welding distortion were obviously different. Wang et al. proposed a framework of computational approach based on welding buckling investigation during fabrication of the ship panel [11]. As the practical technique, intermittent welding procedure was employed to decrease the magnitude of welding inherent deformation, and avoided the welding induced buckling. Huang et al. [12] tried to reduce the overwelding and distortion for naval surface combatants in the U.S. shipbuilding industry on thin steels. Park and Lee [13] studied on the fatigue strength of ship structural steel with gusset welds. Assessed fatigue property by the static overload and average load in the fillet welded joints on the ship structural steel. The weld stress concentration factor and property were developed to investigate the relation between overload and fatigue strength. Moreover, weld shrinkage data models were developed [14] for thin uniform and 
complex ship panels to predict in-plane shrinkage. The complex features in the thin panels included cutouts, inserts, multiple thicknesses, and nonrectangular-shaped panels. The users could provide fabrication details such as the welding process, weld sizes, welding parameters, and the use of fixtures. Oh et al. combined QFD (quality function deployment) and TRIZ for the development of an exportable modular building system [15]. The results showed that the new method reduced the volume of an exportable modular building system compatible with ISO (International Organization for Standardization) container shipping by $48 \%$ and decreased the weight of structural steel by $30 \%$. Lou et al. [16] used TRIZ to build the pneumatic propeller ship while applying STEM (science, technology, engineering, and mathematics) knowledge. An online TRIZ platform was created for the pneumatic propeller ship project. Group interviews and questionnaires were conducted for data collection and analysis. However, none of the above researches combine the legal rules for proper improvement.

Most studies focus on the technical enhancement. By a different point of view, this study follows the hull structure of rules for the Construction and Classification of Steel Ships [17] issued by the China Corporation Register of Shipping. This research combines codes, operating standards, pressure test plan, and an alternative scheme with management theory to improve the welding process for a fillet air test.

\section{Research Method}

This study improved the new ship manufacturing process, with a goal to increase production efficiency. The research method uses TRIZ as the main axis, as shown in Figure 1. First, the problem hierarchy analysis was used to define the problem, the physical contradiction pattern in the problem was analyzed, and the problem hierarchy analysis rules were used to seek a solution. Afterwards, the 39 engineering parameters and 40 invention rules of TRIZ were used to seek a feasible solution in the contradiction matrix, and the feasible solution was embodied into the actual solution [18]. Finally, the benefit assessment was implemented. If the anticipated benefit is reached, the SOP (standard operation procedure) is established and the improvement continues. If the anticipated benefit is not reached, the TRIZ is used circularly to seek an innovative improvement method [19]. Related research methods and tools are described below.

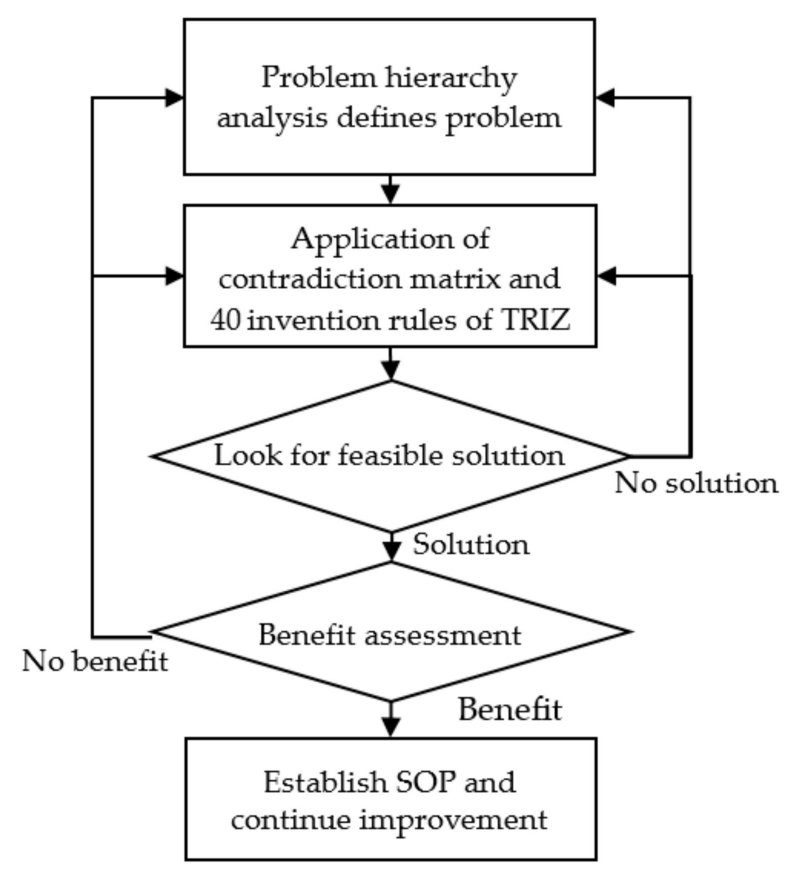

Figure 1. Research process. 
TRIZ is the abbreviation for Teoriya Resheniya Izobreatatelskikh Zadatch in Russian, explained as the theory of inventive problem solving. TRIZ was proposed by GenrichAltshuller, a Russian mechanical engineer in 1946, as a new invention process for analyzing patent documents and concluding method to address the product innovation principles [20]. In other words, TRIZ is a problem-solving tool; it is a philosophy, a systematic thinking method, composed of many tools (e.g., 40 inventive principles, contradiction matrix) [21]. The innovation rules of TRIZ can provide designers with a set of systematic rules as design criteria, so as to develop new conceptions to solve problems.

In the TRIZ method, the major function of problem hierarchy analysis [21] is to redefine and assist in clarifying the potential by-problems of a target problem, laying emphasis on seeking the incentivizing solutions to and factors underlying the problem. Hence, the target problem is expanded (enlarged) and focused (diminished) simultaneously based on two questions, which are: "Why do I want to solve this problem? and Why else?" and "What's stopping me solving this problem? and What else?". Hence, there is the probability of solving the original problem on other expanded or focused hierarchies, as shown in Figure 2. In terms of expansion of hierarchy, the incentive to solve this problem is continuously inquired upwards with the original problem grid (at the middle) as the starting point, and, then, the original problem is expanded gradually. Hence, the cause of the problem and more specific problems that may arise by solving the problem are repeatedly analyzed downward, the original problem becomes gradually focused on.

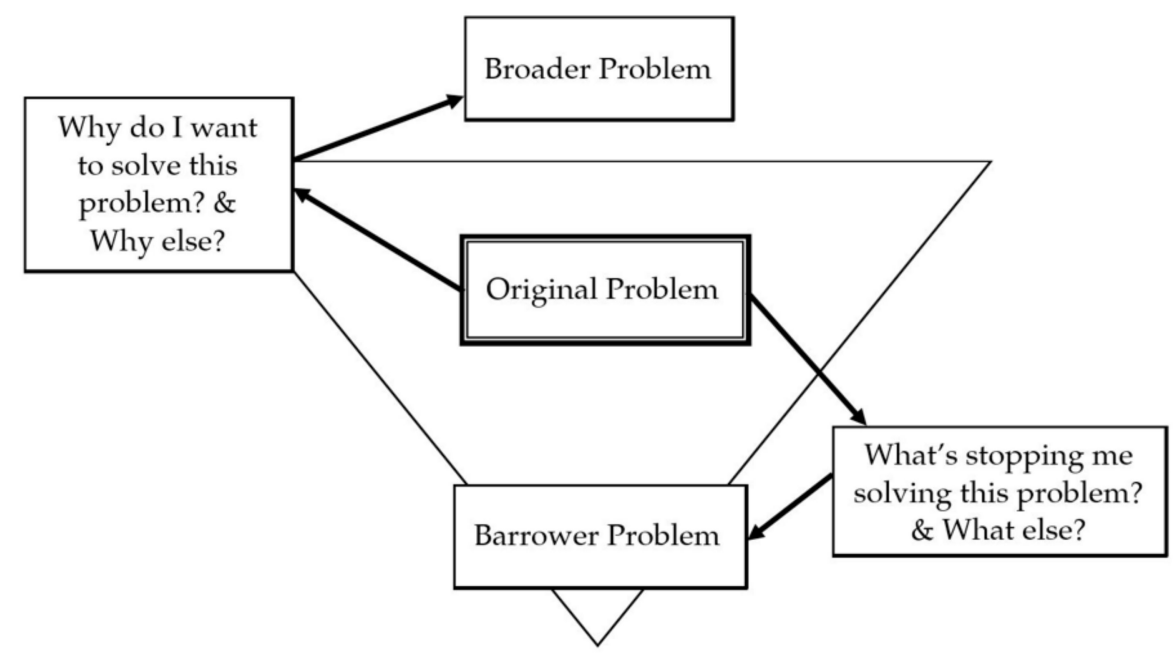

Figure 2. Problem hierarchy analysis.

The contradiction matrix is always a powerful problem-solving tool in the TRIZ method. A common situation in the problem-solving process is that the attempt to improve an item results in the deterioration of another item or the "requirement conflicts" of opposite properties occur simultaneously, that is, the "contradictions" [22]. The contradiction matrix was invented to eliminate technical contradictions.

1. 39 engineering parameters:

The items to be improved or the items that got deteriorated as a result of improvement comprise the engineering parameters. These parameters make up one of the major components of the contradiction matrix. Altshuller induced 39 engineering parameters from the research on patents; hence, the early contradiction matrix was generally used for solving engineering problems.

2. 40 inventive principles:

The 40 inventive principles are one of the important problem-solving tools of the TRIZ method. Based on their use in the domain of engineering in the past 50 years, Kuroshi and Ölçer [23] indicates that, at present, the 40 invention rules have dual purposes: 
- The fundamental purpose of each principle is to guide the user to conceptually or practically change a specific situation or system, so as to attain the goal for problem-solving.

- The 40 inventive principles train the user to think in analog mode; the 40 inventive principles can be detached from the domain of engineering through analog thinking, and used for problem-solving in various domains.

\section{Case Study and Analysis}

This study performed TRIZ improvement for the new ship process bottleneck station of the sample company. The research process and method are described below:

\subsection{Introduction to the Research Case}

The sample company in this study is the biggest shipbuilder in Taiwan, its primary services include commercial ships, official naval vessels, and special ships. The design development or shipbuilding and warship building engineering technologies have reached the level of large ship builders in the world, therefore, this research's findings could provide related industries with references. The project team comprised 15 persons from this study and the primary and secondary superintendents of the sample company (including engineering and design department, layout division, hull factory, quality assurance division, labor safety and health department, and dock chamber). All members of the team jointly studied the "new ship process bottleneck station TRIZ improvement project".

The large commercial ship construction method of the sample company is shown in Figure 3. First, the BLOCK construction was performed in a land-based factory building; the construction process includes: processing imported materials, subassembly production, BLOCK combination, structure delivery inspection, outfit assembly, land-based painting, and so on. Afterwards, the grand assembly operation was performed in the dock, the blocks were hoisted and combined and mounted in the dock. The final steps are launching, running tests, and ship delivery. Based on these, the project team discusses the operational bottlenecks operation in the construction process.

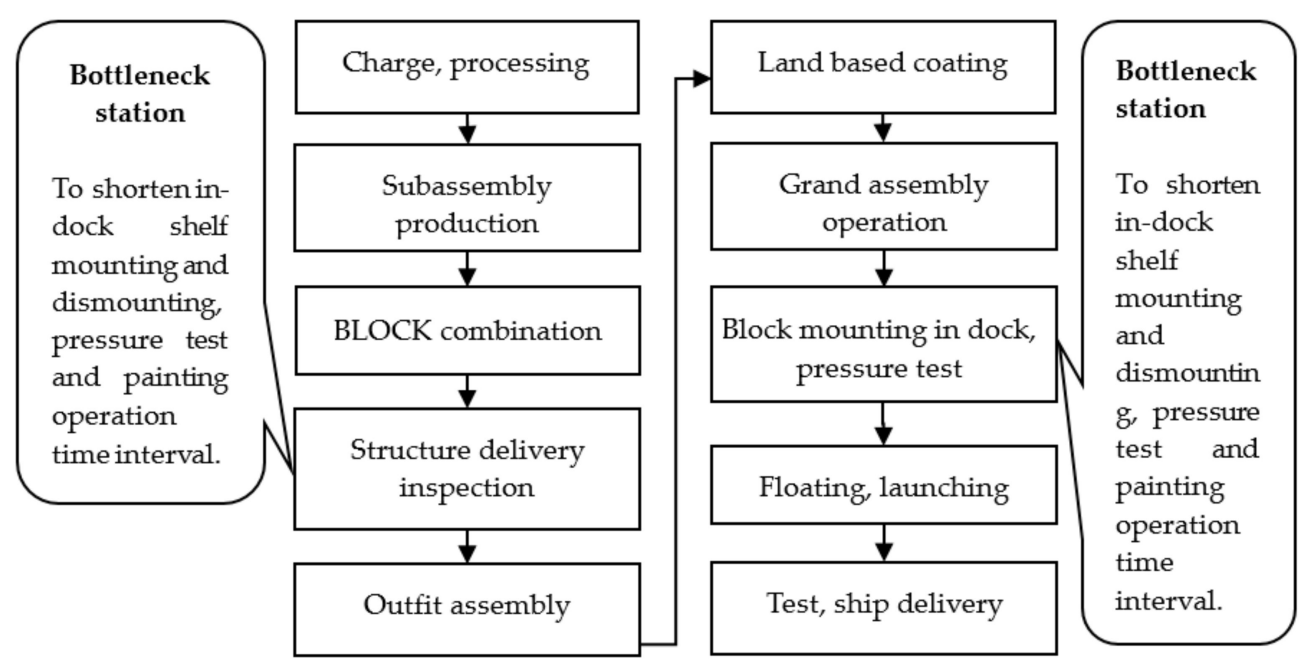

Figure 3. Commercial ship production flow of the sample company.

The sample company project team note that the ship structures are mostly made of carbon steel material. Without a favorable coating for protection, the seawater will accelerate oxidation corrosion [24]. Therefore, to upgrade the coating quality and reduce the coating damage, a complete planning is required before block hoisting; hence, all of the components and pipe fittings shall be finished before the painting stage. Ideally, the painting operation in dock is only block merging. However, the shipowner's design modifications or control and inspection system reset sometimes leads to site operation modification, hence, influencing the coating quality. 
The sample company is faced with a problem in the structure construction stage. Since the ship has different functional compartments, the water tightness of each compartment is of absolute importance to the ship itself [25]. Besides, the ship manufacturing process must comply with the shipowner- and classification-approved TANKS TEST PLAN. Therefore, multiform pressure tests were performed, so as to meet performance and regulation requirements. As a result, the compartment bead shall not be painted before the pressure test is finished, so as to facilitate the bead inspection operation [26]. The BLOCK pressure test process of the sample company is shown in Figure 4.

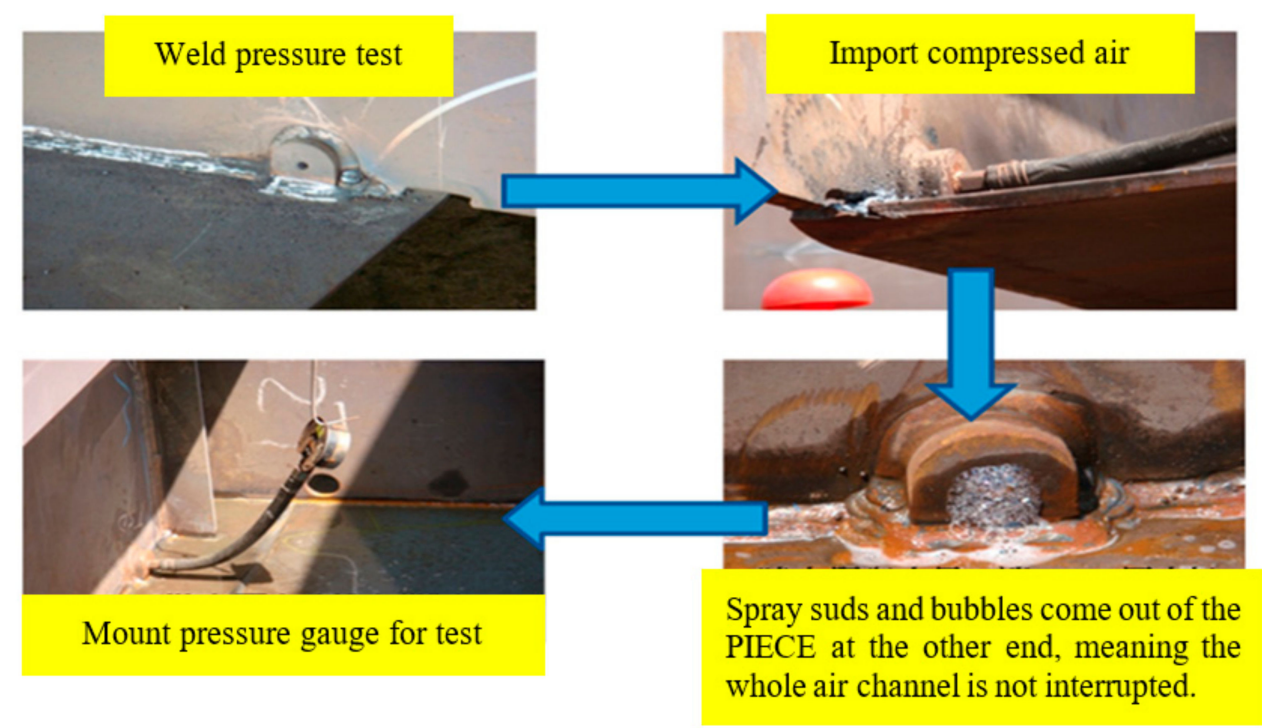

Figure 4. BLOCK pressure test flowchart.

The operating method involved the pressure test PIECE being welded on the front and rear ends of the longitudinal bulkhead, and then the pressure test hole was sealed by welding. Therefore, the present practice of sample company was that after the BLOCK sandblasting operation, all watertight bulkhead beads should be tested before painting. First, the bead was protected by rubberized cloth, and precoated with a layer of primer. When the pressure test was finished for the whole compartment, the cleaning, rust grinding, painting, and delivery inspection were performed again for the compartment beads. Finally, the coating protection operation was completed. However, the pressure test inspection and paintwork process increased shelf mounting and dismounting workload, thereby, consuming considerable labor and work hours and significantly influencing subsequent operation. This is a major bottleneck in the shipbuilding process.

In view of this, the sample company project team notes that the compartment bead inspection process must be classified as primary improvement item for subsequent TRIZ application and improvement analysis.

In the problem analysis, the BLOCK pressure test selected in this study is shown in Figure 4 . The traditional operating mode performed bead pressure test operation while refitting the compartment fillet weld pressure test operation in the BLOCK stage. The correlation between each assembly and resources in this original operation flow was made into a model view by the "substance-field analysis" of TRIZ, and the potential solution of the problem was explored from the model point of view. Finally, problem-solving was deduced using TRIZ, so as to obtain the overall architecture of problem improvement.

\subsection{Problem Hierarchy Analysis}

The original problem was focused and expanded to seek different solution opportunities embedded in the problem, as shown in Figure 5. According to review, when the pressure test operation workload increased, although the conventional pressure test PIECE 
had not leaked the watertight compartment was overspread, the esthetical appearance and painting operation were influenced, and the operating cost was increased greatly. This provides another avenue for seeking problem-solving.

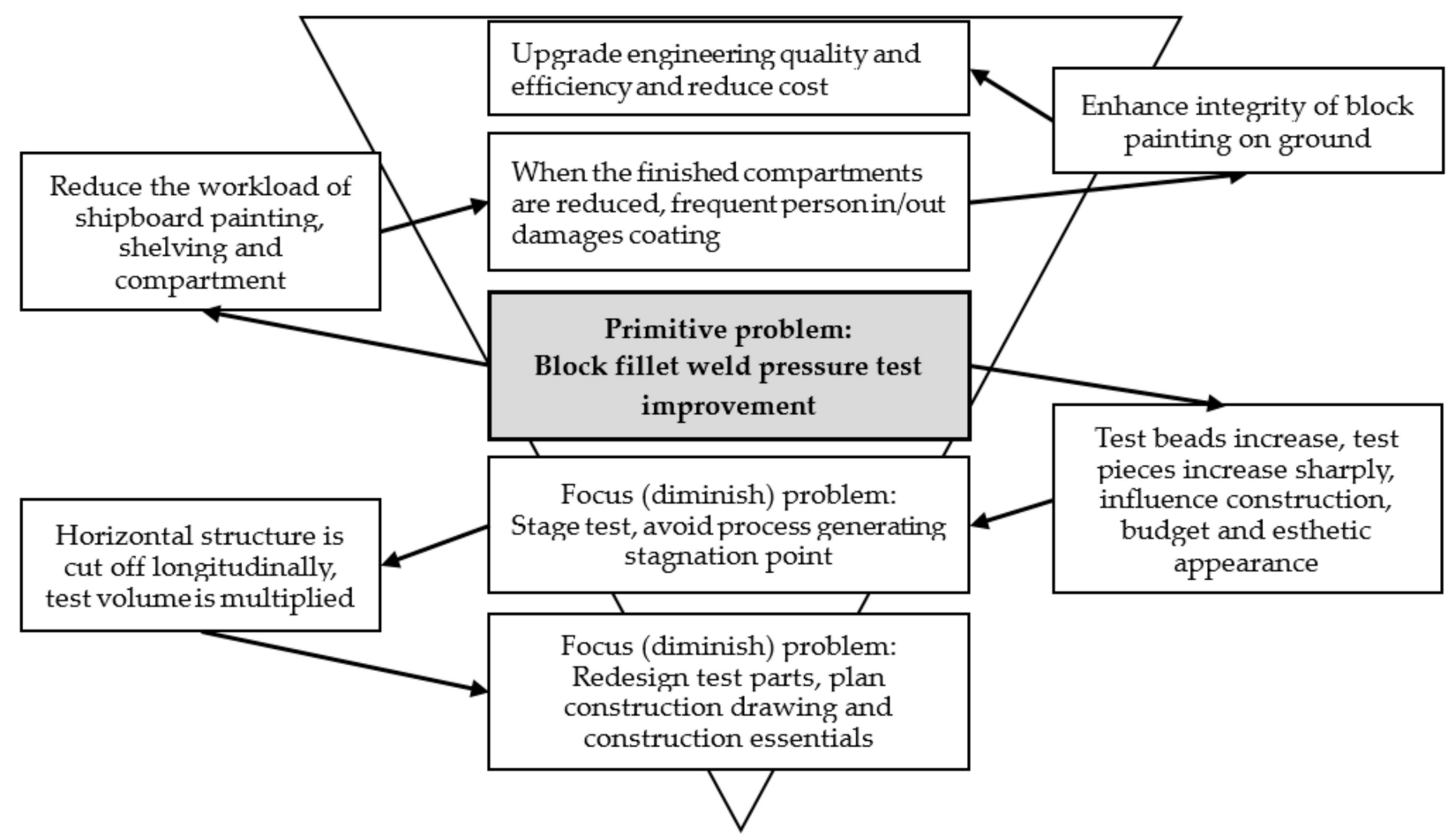

Figure 5. Problem hierarchy analysis diagram.

According to the analysis results of the problem hierarchy analysis, the BLOCK fillet weld pressure test improvement will influence the redesign of test parts. It will also influence the planning of construction drawing and construction essentials and upgrading engineering quality. In addition, it influences efficiency and cost reduction significantly.

\subsection{TRIZ Application}

This research team only examined the longitudinal compartment according to traditional practice, the TRIZ problem-solving process was used, and the analyzed parameters to be improved include engineering parameters No. 25: waste of time and No. 39: productivity. The parameters not to be worsened include: No. 28: measurement precision and No. 37: complexity of control. The technical contradiction matrix table is shown in Table 1. Followed by contradiction matrix table [20], the horizontal axes are the parameters not to be worsened (found from 39 engineering parameters) and the vertical axes are the parameters to be improved (found from 39 engineering parameters, also) for solving intentions in this research problem. The numbers in the text are the matched specific principles in 40 principles. These mean the principle 1 (segmentation), principle 2 (taking out), principle 10 (preliminary action), principle 18 (mechanical vibration), principle 24 (intermediary), principle 27 (cheap short-living objects), principle 28 (mechanics substitution), principle 31 (porous materials), principle 32 (color changes), principle 34 (discarding and recovering), and principle 35 (parameter changes) are the suggested improvement direction.

Table 1. Technical contradiction matrix table.

\begin{tabular}{|c|c|c|}
\hline $\begin{array}{l}\text { The Parameters Not to Be Worsened } \\
\text { The Parameters to Be Improved }\end{array}$ & $\begin{array}{l}\text { No. 28: } \\
\text { Measurement Precision }\end{array}$ & $\begin{array}{c}\text { No. 37: } \\
\text { Complexity of Control }\end{array}$ \\
\hline No. 25: waste of time & $24,34,28,32$ & $18,28,31,10$ \\
\hline No. 39: productivity & $1,10,34,28$ & $35,18,27,2$ \\
\hline
\end{tabular}


The research team checked all these suggested invention principles by TRIZ. Accounting to the experience and analysis by the team members, the team found the \#18 (mechanical vibration), \#28 (mechanics substitution), \#31 (porous materials), \#32 (color changes), and \#34 (discarding and recovering) are infeasible for solving our issue. Therefore, the team decided not to use these infeasible principles. For other feasible principles, this research team compiles the activity planning into the following six major items according to the aforesaid results.

\subsubsection{Design Mix}

The present filling board and angular cut forms are as shown in Figure 6. The original end of the filling board is bevelled for welding, the angular cut is modified for the longitudinal bead to penetrate, and the angular cut is changed due to plate thickness difference.

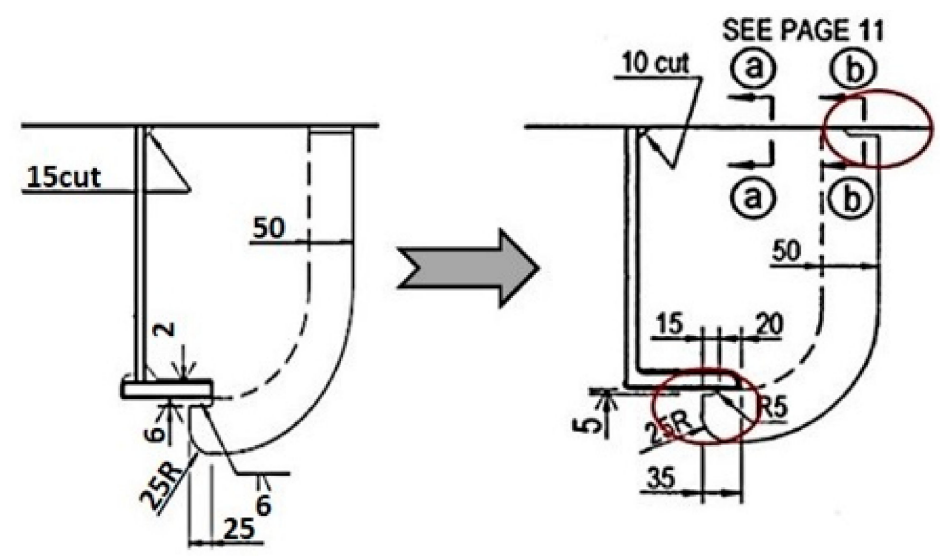

Figure 6. Design drawings for the changed form of filling.

Working on the drawing agreement stage, the pressure test positions are planned, and the pressure test symbols are indicated in the working drawing, as shown in Figure 7. The cut plan projects the pressure test symbols on the board. Various stages of pressure test operation fit for the pressure test are in the working drawing, and the intubation and pressure test operation are performed as per the drawing.

\subsubsection{Pressure Test Data Establishment}

The new ship pressure test operation was performed by quoting the deduced \#1: Segmentation, \#2: Taking out, and \#24: Intermediary. The engineer establishes the LIST fitting the working drawing, as shown in Figure 8. The pressure test information of each block is built in the production system by LIST, so that the production line managers can know the positions and workload from the stereogram, as shown in Figure 9, contributing to work preparation and implementation.

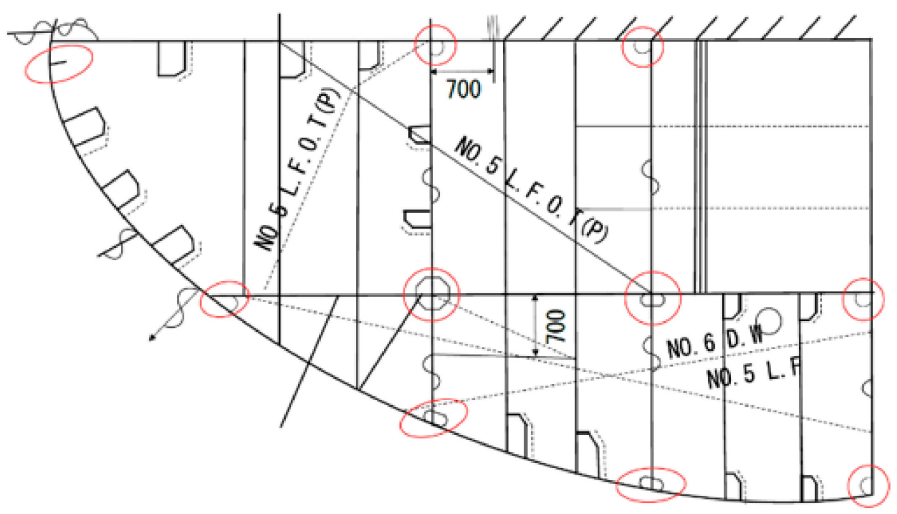

Figure 7. Pressure test position marks in working. 


\begin{tabular}{|c|c|c|c|c|c|c|c|c|c|c|c|c|c|c|c|c|c|c|c|}
\hline \multirow{4}{*}{ Term } & \multirow{4}{*}{ BLOCK } & \multirow{4}{*}{$\begin{array}{l}\text { Operation } \\
\text { Optage } \\
\text { Content }\end{array}$} & \multicolumn{17}{|c|}{ Fillet Test } \\
\hline & & & \multicolumn{7}{|c|}{ SUB } & \multicolumn{6}{|c|}{ BLOCK-A } & \multicolumn{4}{|c|}{$\mathrm{BLOCF}$} \\
\hline & & & \multirow[b]{2}{*}{$\mathrm{P}$} & \multirow[b]{2}{*}{$\begin{array}{l}\text { Welat } \\
\text { benst }\end{array}$} & \multirow[b]{2}{*}{ 列 } & \multirow[b]{2}{*}{$\begin{array}{l}\text { Weltugh } \\
\text { lenght }\end{array}$} & \multirow{2}{*}{$\begin{array}{l}\text { Total } \\
\text { lenght } \\
\text { of S }\end{array}$} & \multicolumn{2}{|c|}{ confirm } & \multirow[b]{2}{*}{$\mathrm{P}$} & \multirow[b]{2}{*}{ 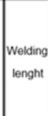 } & \multirow[b]{2}{*}{$S$} & \multirow{2}{*}{$\begin{array}{l}\text { Weltang } \\
\text { lenghn }\end{array}$} & \multirow{2}{*}{ 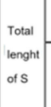 } & confirm & \multirow{2}{*}{\multicolumn{2}{|c|}{ 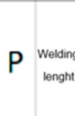 }} & \multirow[b]{2}{*}{ S } & \multirow[b]{2}{*}{ 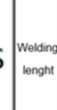 } \\
\hline & & & & & & & & $\mathrm{P}$ & $\mathrm{s}$ & & & & & & $\mathrm{PS}$ & & & & \\
\hline 1 & $\mathrm{D} 1{ }^{*} \mathrm{~B} 1{ }^{*} \mathrm{~B} 1 \mathrm{BK}$ & D1-L19-BW-41P & 1 & & 1 & & & & & 1 & & 1 & & & & & & & \\
\hline 2 & & D1-L19-BW & 1 & & 1 & & & & & 1 & & 1 & & & & & & & \\
\hline 3 & & D1-L19 & & & & & & & & 2 & & 2 & & & & 1 & 1 & 1 & \\
\hline 4 & & D1-L16 & & & & & & & & 1 & & 1 & & & & & & & \\
\hline 5 & & D1-L4 & & & & & & & & 1 & & 1 & & & & 1 & 1 & 1 & \\
\hline 6 & & Welding total length & & & & & & & & & & & & & & & & & \\
\hline 7 & $\mathrm{D} 2{ }^{*} \mathrm{~B} 2{ }^{*} \mathrm{~B} 2 \mathrm{BK}$ & D2-L7-F70 & 1 & & 1 & & & & & 2 & & 2 & & & & 1 & 1 & 1 & \\
\hline 8 & & D2-L10-F70 & 1 & & 1 & & & & & 2 & & 2 & & & & 1 & $\mathbf{L}$ & 1 & \\
\hline 9 & & D2-L13-F70 & 1 & & 1 & & & & & 2 & & 2 & & & & 1 & 1 & 1 & \\
\hline 0 & & D2-L16-F70 & 1 & & 1 & & & & & 2 & & 2 & & & & 1 & 1 & 1 & \\
\hline
\end{tabular}

Figure 8. Working drawing LIST.

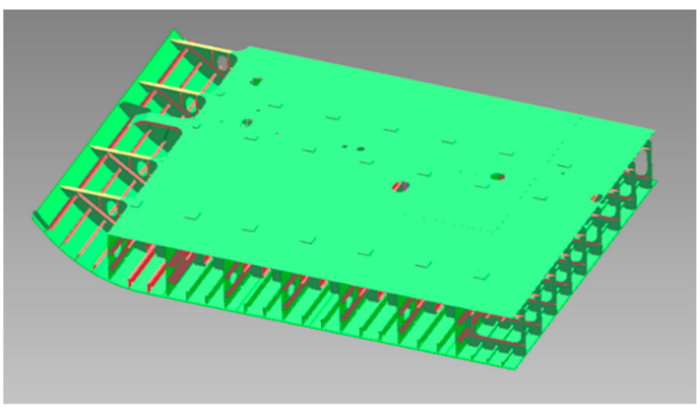

Figure 9. Block stereogram.

The BLOCK pressure test principle is deduced from \#10: Preliminary action, according to the pressure test LIST, the draftsmen make the subassembly (Figure 10), A engineering (Figure 11) and B engineering (Figure 12), and various stages of pressure test working drawings, so that the onsite constructors can recognize the pressure test position quickly from the stereogram, and plan the construction and acceptance fields in the table to record the operation process. The shipowner signs and keeps the record as a completion record and the basis of future tracking.

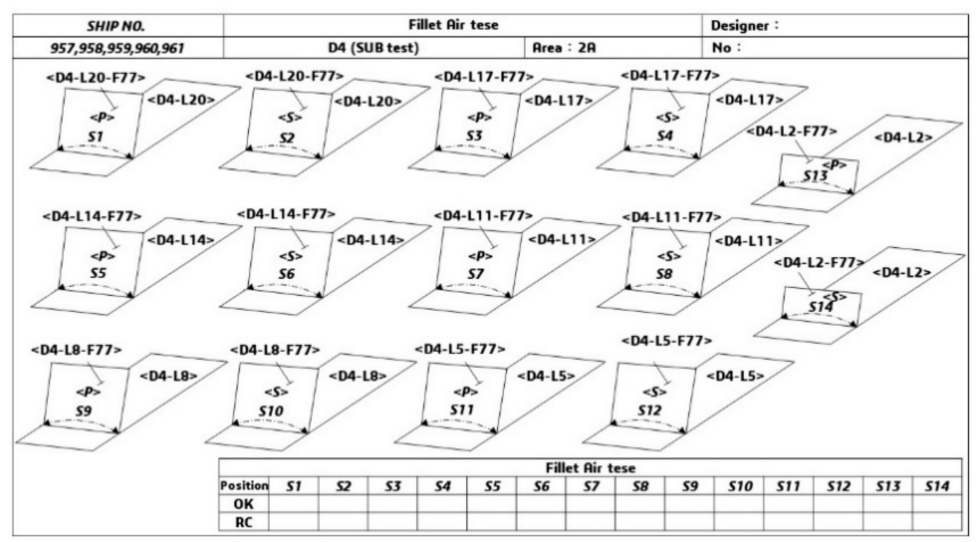

Figure 10. Group pressure test working. 


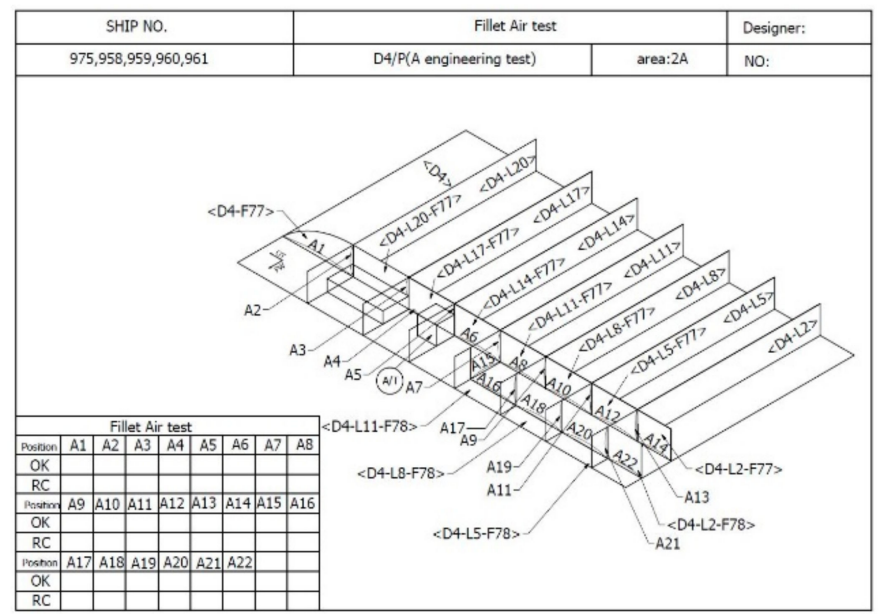

Figure 11. A engineering pressure test.

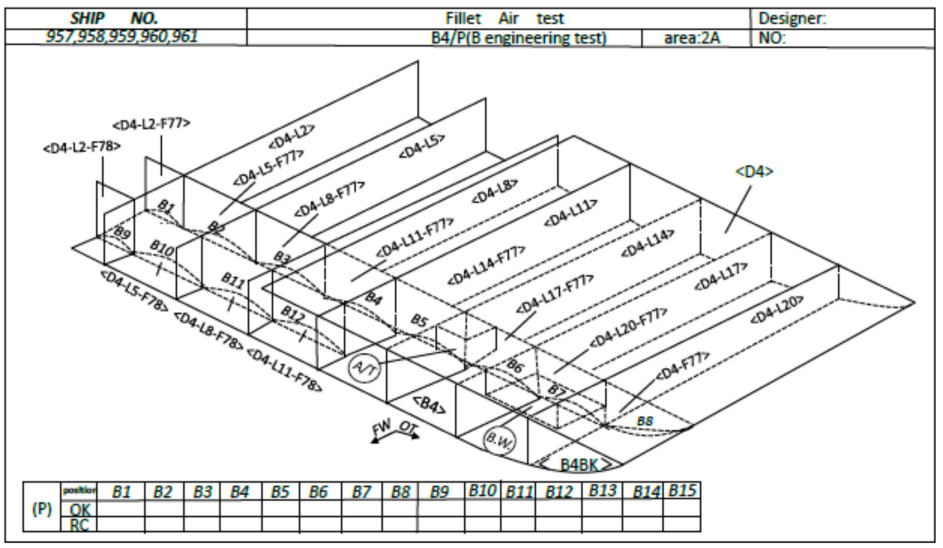

Figure 12. B engineering pressure test.

\subsubsection{Pressure Test Part Improvement}

According to the analysis, when the traditional pressure test PIECE completed the pressure test, the air-intake duct and pressure gauge were disassembled, the subsequent operation was complicated, and only the bolt hole in the PIECE was closed up by electric welding in the block. However, in the old process, one block has at most six (6) pieces, while the new process will have at most 60 pieces. Therefore, the graduate students use important problem-solving tools of the 40 inventive principles of the TRIZ method, \#24: Intermediary, \#34: Discarding and recovering, and \#27: Cheap short-living objects, to design different pressure test fixture combinations, so as to respond to this change.

The original pressure test PIECE is replaced by a seamless carbon steel tube, as shown in Figure 13. The unit price of steel tube is US\$1.7/PIECE, higher than the unit price, US\$0.5, of a PIECE, but the PIECE cannot be recovered as the BLOCK flows out. However, the steel tube can be reused over 15 times after dew removal, the better technique exceeds 20 times, thus, the cost is obviously lower.

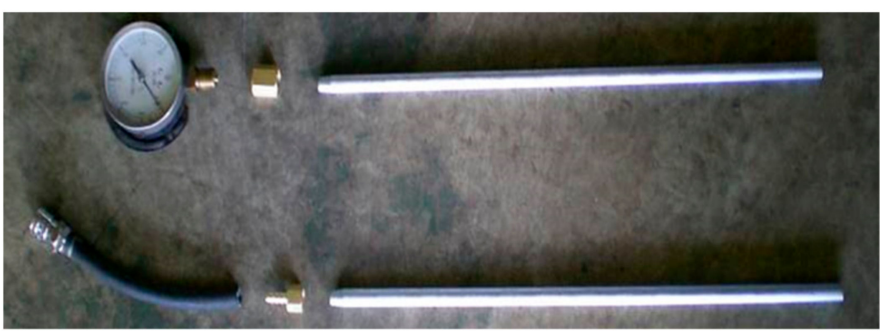

Figure 13. New pressure test part. 


\subsubsection{Division of Work of Pressure Test Stage}

For \#2: Taking out, as the pressure test workload increases suddenly, the pressure test operation is all checked before block painting according to traditional practice, however, a severe bottleneck in the production flow is formed in the BLOCK delivery inspection process. In order to break through the process bottleneck, this case uses \#1: Segmentation of the 40 rules, the bottleneck is enlarged to accelerate circulation, so this operation must be redistributed in each stage to relieve the bottleneck. The pressure test inspection is finished in the subassembly the A engineering and B engineering of the BLOCK assembly stage to minimize the impact of workload increase.

\subsubsection{Intubation and Electric Welding}

From subassembly to BLOCK molding stages, the ironwork operation shall perform blending, assembly, and spot welding according to the working drawing. The pressure test intubation operation is merged into this stage. In the ironwork assembly operation, as shown in Figure 14, the steel tube was mounted by spot welding according to the indicated positions in the working drawing for assembly operation.

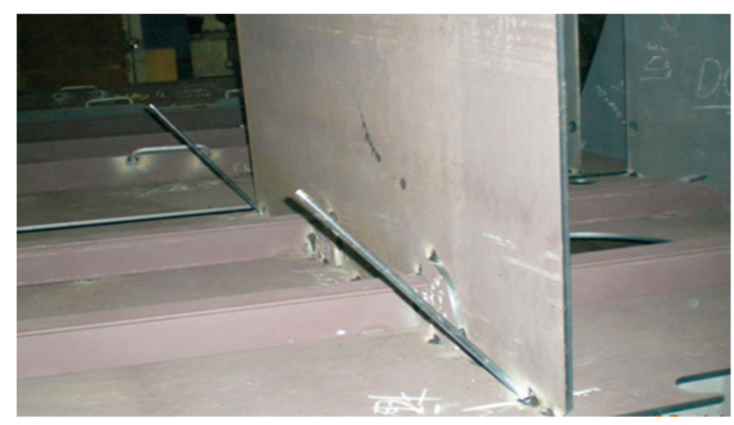

Figure 14. Ironwork PIECE device.

The pressure test steel tube was fixed by ironwork spot welding, in order to guarantee the consistency of electric welding workmanship. As shown in Figure 15, the pressure test steel tube was welded to the fillet weld in the electric welding operation.

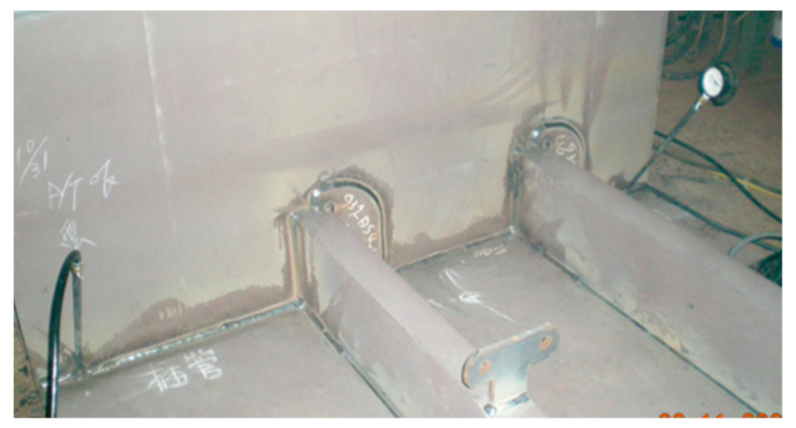

Figure 15. Weld PIECE.

\subsubsection{Test, Delivery Inspection, and Backfill}

The pressure test operator mounts the compressed air joint and pressure gauge on the steel tubes at two side ends of the test position, as shown in Figure 16. When the compressed air was imported into one end, and the pressure gauge index reached the standard value, the compressed air was intercepted in the bead, and then the suds were used to check for leaks, where necessary, remedial work was performed. The pressure value in the modified pressure gauge remains shall be observed, if it decreases, there is a leak in the bead, and a retest is required. 


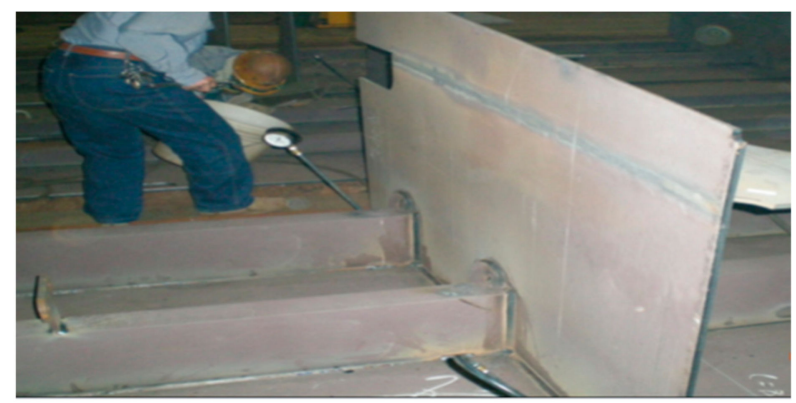

Figure 16. Test.

When the internal review operation was completed, the delivery inspection could be submitted. The delivery inspection data were imported into the company delivery inspection system and the resident regulatory representatives together with the shipowner perform reinspection and approval of the workpiece according to the requested inspection time, as shown in Figure 17.

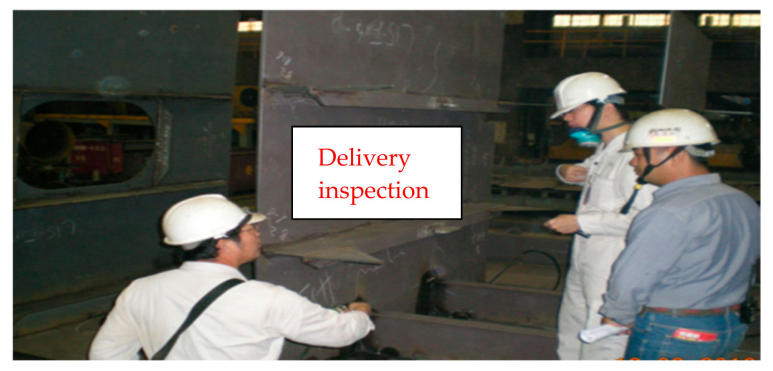

Figure 17. Delivery inspection by the shipowner and team.

When the delivery inspection was completed, the steel tube leak was removed, and the bead backfilling work was performed according to standard operation, as shown in Figures 18 and 19. This steel tube was reused after leak removal until it could not be reused anymore.

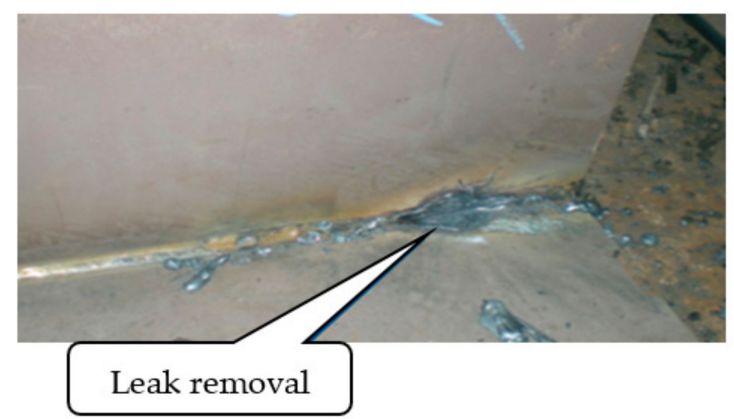

Figure 18. Piece leak removal. 


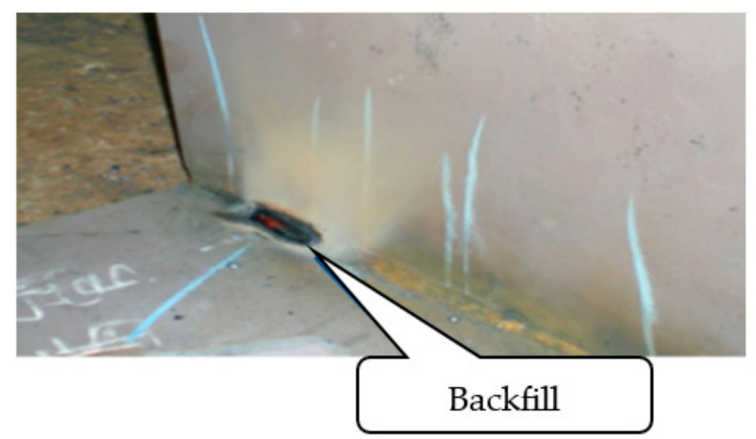

Figure 19. Bead backfill.

If there were omissions or discrepancies in the worksheet for the manufacturing process of the new ship type, the worksheet could give feedback to the draftsmen. Any engineering problem like infiltration or failed inspection must be fed back to the downstream via the worksheet, attached to the finished compartment by rubberized cloth after sandblast and valid pressure test.

The fillet weld pressure test was used in the company for years, hence, this operating mode improvement shall be innovative. While all of the drawings were made manually, the present drawing information could be linked to the design information system, this ensures data accuracy [27].

\section{Benefit Analysis}

The benefit analysis for this new ship process bottleneck station's TRIZ improvement project-fillet weld pressure test process improvement-was described in terms of costsaving and increase in operational cost. The cost saving aspects include: (1) reducing hoisting and shelving operations, (2) reducing the labor and material costs of overground precoating primer and cloth attachment of painting workshop (including rain-induced delay, which is reduced by early painting operation as the working time is shortened), (3) the watertight FRAME and the whole BLOCK can be painted simultaneously in the overground stage, hence, upgrading the painting quality, (4) reducing the shipboard painting workload, thereby, saving cost, (5) reducing paint damage at the shipboard stage, (6) economizing pressure test workload during mounting, (7) shortening working time in dock, which is helpful for increasing annual output, (8) solving high cost outlay and engineering delay as a result of another sandblast, thus, not exceeding the PSPC (performance standards for protective coating) specification: "in-DOCK water tank rust removal paint area $<2 \%$ ". In addition, increase in the operating cost is reflected as follows: (1) increasing combination workshop operation and cost and (2) influencing subregion construction schedule and smoothness. The actual implementation effects were described subsequently.

\section{Cost-Saving Implementation Effect}

The comparison basis of the performance of this study sample was the comparison between the 8000TEU and 4500TEU series ships built by a Taiwan shipbuilder between 2015 and 2017 and the newly built sister ships in more recent years for economization and shortening of operation schedule. The new ship schedule in the dock of the company uses two ships with the same grade operation, each grade is 10-12 weeks, according to the ship size, so there are 4.5 grades per year. The actual implementation effect of various stages of ground painting operation, shelving operation, compartment pressure test operation in dock, shipboard painting operation, saving operations, and indoor work block increase operations is described as follows:

1. Ground painting operation saved amount:

The pressure test qualified bead can be painted directly after the sandblast, saving the primer coating, cloth attachment cost $(25 \mathrm{M} /$ roll; US $\$ 1.8 /$ roll), and salary (by US $\$ 8.3$ 
per hour). As shown in Table 2, each grade saves US\$3446, the amount saved annually is US\$15,507.

2. Shelving operation saved amount:

The pressure test detection and painting operation higher than $2 \mathrm{M}$ is required of shelves on the front and rear sides of compartment. When the land-based pressure test is completed, the shelves only leave the butt bead, the others can be cancelled. According to the annual labor service unit, the procurement cost of a hoisting workshop and the labor service unit price of each stage plank is US\$9, as shown in Table 2. Each grade saves US $\$ 19,586$, the saved amount annually is US $\$ 88,137$. In addition, according to the interview with shelving contractors, the shelf dismounting operation after painting is carried out carefully to avoid damaging the coating. Therefore, this improvement project creates considerable profit for the shelf dismounting contractors.

3. In-dock compartment pressure test operation saved amount:

The overall watertight compartment is to be tested, modified, and inspected for the cabin pressure test in dock. After the land-based pressure test is completed, the pressure test operation range of finished compartment is only the BLOCK joint test. According to the investigation on the mounting workshop pressure test squad, it is conservatively estimated that each compartment saves about 10 work hours, US\$8.3 per hour, 4.5 grades of ships per year. As shown in Table 2, each grade saves US\$5166, the saved amount annually is US\$23,247.

4. Shipboard painting operation saved amount:

The compartment painting workload of the shipboard painting operation only is executed after block hoisting in-dock. Hence, the workload of the compartment after pressure test operation is all saved. The rust removal, painting and paintwork of the watertight compartment will also be significantly saved. As shown in Table 2, each grade saves US $\$ 208,915$, the amount saved annually is US\$940,118.

This improvement project results in a sudden increase in the pressure test workload, which becomes a bottleneck in delivery inspection stage. To increase the overall production efficiency of shipbuilding, this study sample used TRIZ to arrive at a solution. The production bottleneck workload was moderately dispersed to various stages. In the indoor work BLOCK production stage, the outsourcing operation amount will be increased in response to the fillet weld pressure test operation. According to onsite evaluation, the labor service unit price of the bead pressure test is US $\$ 13.3$ per bead. As shown in Table 2, each grade of this operation increases US $\$ 39,573$ andUS $\$ 7585$. Hence, the increased amount annually is US\$178,079 and US\$34,133; total increased US\$212,212 at the indoor work stage.

By summarized all saving and increasing in Table 2, each grade can save US\$230,738 and total annual saving are US $\$ 1,038,321$. This research makes a great improvement of reducing the destruction of the paint under the integrity of the painting quality. 
Table 2. Total benefit statistics (compared with sister ship).

\begin{tabular}{|c|c|c|c|c|c|}
\hline \multirow{2}{*}{\multicolumn{2}{|c|}{ Job Content Description }} & \multicolumn{2}{|c|}{ Computing Equation for Each Grade of Ship (US\$) } & \multirow{2}{*}{$\begin{array}{c}\text { One Grade } \\
\text { Economization (US\$) }\end{array}$} & \multirow{2}{*}{$\begin{array}{l}\text { Annual (4.5 Grades) } \\
\text { (US\$) }\end{array}$} \\
\hline & & (8626TEU) & (4500TEU) & & \\
\hline \multirow{2}{*}{ Ground painting operation } & $\begin{array}{l}\text { Attached cloth length: } 25 \mathrm{M} / \text { roll; } \\
\text { US } \$ 1.8 / \text { roll. }\end{array}$ & $\begin{array}{c}13,748^{*} 2 / 25 \mathrm{M}^{*} 1.8(\mathrm{US}) \\
=2016\end{array}$ & $\begin{array}{l}9755^{*} 2 / 25 \mathrm{M}^{*} 1.8(\mathrm{US}) \\
=1430\end{array}$ & 3446 & 15,507 \\
\hline & $\begin{array}{c}\text { Labor: } 1 \mathrm{MH} / 20 \mathrm{M} ; \mathrm{US} \$ 8.3 / \mathrm{MH} \\
\text { (subcontractor) }\end{array}$ & $\begin{array}{l}13,748^{*} 2 / 20 \mathrm{M}^{*} 8.3(\mathrm{US}) \\
=11,457\end{array}$ & $\begin{array}{c}9755^{\prime *} 2 / 20 \mathrm{M}^{*} 8.3(\mathrm{US}) \\
=8129\end{array}$ & 19,586 & 88,137 \\
\hline Shelving operation & $\begin{array}{l}\text { Double-sided shelving of compartment } \\
\text { is reduced to single-sided (Unit cost: } \\
\text { US\$9) }\end{array}$ & $\begin{array}{l}1140(\mathrm{PC}) * 9(\mathrm{US}) \\
\quad=10,260\end{array}$ & $\begin{array}{l}780(\mathrm{PC})^{* 9}(\mathrm{US}) \\
\quad=7020\end{array}$ & 17,280 & 77,760 \\
\hline $\begin{array}{l}\text { Compartment pressure test } \\
\text { operation in-dock }\end{array}$ & $\begin{array}{l}\text { US8.3/MH, Average economization: } \\
\text { compartment/10 MH }\end{array}$ & $\begin{array}{l}10 * 33 * 8.3(\mathrm{US} \\
\quad)=2750\end{array}$ & 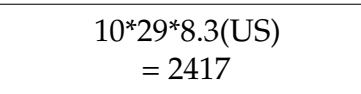 & 5166 & 23,247 \\
\hline \multirow{2}{*}{ Shipboard painting operation } & $\begin{array}{c}1 \mathrm{MH} \text { average rust removal area } \\
=3 \mathrm{M}^{2} ; \mathrm{US} \$ 13.3 / \mathrm{M}_{2}\end{array}$ & $\begin{array}{c}13,748 \mathrm{M}^{*} 2 / 3 \mathrm{M}^{2 *} 13.3(\mathrm{US}) \\
=122,204\end{array}$ & $\begin{array}{c}9755^{\prime} \mathrm{M}^{*} 2 / 3 \mathrm{M}^{2 *} 13.3(\mathrm{US}) \\
=86,711\end{array}$ & 208,915 & 940,118 \\
\hline & $\begin{array}{c}\text { 1MH average painting area }=30 \mathrm{M}^{2} \\
\text { US } \$ 13.3 / \mathrm{M}^{2}\end{array}$ & $\begin{array}{c}13,748 \mathrm{M}^{*} 2 / 30 \mathrm{M}^{2 * 8} .3(\mathrm{US}) \\
=13,748\end{array}$ & $\begin{array}{c}9755^{\prime} \mathrm{M}^{*} 2 / 30 \mathrm{M}^{2 * 8.3(\mathrm{US})} \\
=9755\end{array}$ & 23,503 & 105,764 \\
\hline \multirow{4}{*}{$\begin{array}{l}\text { Indoor work BLOCK } \\
\text { increasing operation }\end{array}$} & $\begin{array}{l}\text { Increase pressure test workload, } \\
\text { bead/US\$13.3 ( } 384 \text { beads to } 1812 \text { beads) }\end{array}$ & $\begin{array}{l}1812 \text { (times)*13.3(US) } \\
=24,160\end{array}$ & $\begin{array}{l}1156 \text { (times)*13.3(US) } \\
=15,413\end{array}$ & $(-39,573)$ & $(-178,079)$ \\
\hline & $\begin{array}{l}\text { The original pressure test PIECE cannot } \\
\text { be recovered, Unit cost: US } \$ 1.2\end{array}$ & $\begin{array}{l}1812 * 2(\mathrm{PC}) * 1.2(\mathrm{US}) \\
=4349\end{array}$ & $\begin{array}{l}1156 * 2(\mathrm{PC}) * 1.2(\mathrm{US}) \\
=2774\end{array}$ & $(-7585)$ & $(-34,133)$ \\
\hline & $\begin{array}{l}\text { The replanned pressure test steel tube } \\
\text { can be reused } 15 \text { times, Unit cost: US } \$ 1.7\end{array}$ & $\begin{array}{c}1812 * 2(\mathrm{PC}) * 1.7(\mathrm{US}) / 15 \\
=411\end{array}$ & $\begin{array}{c}1156^{*} 2(\mathrm{PC})^{*} 1.7(\mathrm{US}) / 15 \\
=262\end{array}$ & & \\
\hline & & & & 230,738 & $1,038,321$ \\
\hline
\end{tabular}




\section{Conclusions}

This improvement project was modified continuously over two years, from the pressure test part design in advanced construction planning, discussion about fillet weld assembly accuracy, marking of design drawings, and working drawings to the modification of site operation process; all of which were questioned and delayed at various levels. The part purchase at the test stage, design fit communication, site operation problemsolving, and shipowner customer communication together with thorough popularization all consumed considerable mental efforts. The architecture has evolved gradually, and the benefit identified. Hence, relevant improvement results were concluded as follows.

1. This study effectively solved the new ship process bottleneck station problem. To increase production efficiency, it is not required to enlarge the plant, buy new equipment, or increase manpower, there must be a room to break through an operating mode, no matter how long it has been in practice. For this improvement project, fillet weld pressure test process improvement, the TRIZ provides a different innovative thinking direction, solving the traditional process problems, including the operation concept reconstruction of almost a thousand workers, the coordination of trading profits of various subcontractors, and the full cooperation of cutting unit of at the preprocessing stage. The modification process must bear the pressure of resisting change and success or failure, but the joy of its outcome is ineffable. This TRIZ improvement project could save about US $\$ 1,000,000$ annually for the sampled company. In the violently competitive shipbuilding industry, only companies seeking breakthrough and innovation can survive.

2. This study solved fillet weld pressure test process problems, the pressure test efficiency was increased effectively, and the block painting cost was saved. This improvement project used TRIZ to solve the fillet weld pressure test process problems, the pressure test was completed thoroughly, so that the BLOCK painting integrity was enhanced comprehensively. In the land-based BLOCK painting operation, the operating cost of precoating primer and pasting and tearing cloth after sandblast could be saved. The BLOCK mounting compartment test operation in-dock only leaves the joint, the measuring range and operating work hours of dock floor in new ship compartment, including reducing almost half of the shelf mounting and dismounting operation and reducing the amount of persons and instruments in the painted compartment as this damages the quality of paint coating.

3. Fillet weld pressure test process improvement, the ballast tank painting quality, and delivery inspection percent of pass were improved effectively. The ballast tank painting quality is the key point required by all supervisors, the traditional compartment bead construction often leaves suds and rust due to pressure test factors. Therefore, the water wash and rust removal are required, and because the operating environment is poor, the workmanship is usually criticized. In addition, the paint overlap of the coating is likely to result in a painting quality defect, so that the ballast tank delivery inspection recheck rate ranks first in the whole ship-painting operation. After this improvement project is implemented, the shipboard compartment painting operation workload in the painting workshop is reduced by about $30 \%$, the shipowner supervisors affirm the improvement of the painting quality, and the ballast tank delivery inspection once-through rate is increased.

Author Contributions: C.-N.W. designed the approach to set up the testing facility. M.-H.H. wrote the initial draft of the paper. C.-F.W. analyzed experimental results in this study. S.-H.W., C.-J.L. conducted experiments and collected results. All authors have read and agreed to the published version of the manuscript.

Funding: This research was partly supported by the National Kaohsiung University of Science and Technology, and MOST 109-2622-E-992-026 from the Ministry of Sciences and Technology in Taiwan. 
Acknowledgments: The authors would like to express our gratitude to National Kaohsiung University of Science and Technology, Ministry of Sciences and Technology in Taiwan.

Conflicts of Interest: The authors declare no conflict of interest.

\section{References}

1. Yin, J.; Shi, J. Seasonality patterns in the container shipping freight rate market. Marit. Policy Manag. 2018, 45, 159-173. [CrossRef]

2. Soyer, B.; Tettenborn, A. Ship Building, Sale and Finance, 1st ed.; Informa Law from Routledge: New York, NY, USA, 2016 ; pp. 45-55.

3. Galliers, R.D.; Leidner, D.E. Strategic Information Management: Challenges and Strategies in Managing Information Systems, 4th ed.; Routledge: New York, NY, USA, 2014; pp. 35-69.

4. Ship and Ocean Industries R\&D Center. The Yearbook of Ship and Ocean Industries RED Center (2017), 1st ed.; SOIC: New Taipei City, Taiwan, 2017; pp. 17-21.

5. Gan, G.; Lee, H.; Lee, L. Network hierarchical DEA with an application to international shipping industry in Taiwan. J. Oper. Res. Soc. 2020, 71, 991-1002. [CrossRef]

6. Rose, C.; Coenen, J. Automatic generation of a section building planning for constructing complex ships in European shipyards. Int. J. Prod. Res. 2016, 54, 6848-6859. [CrossRef]

7. Jin, C.; Wang, Y.; Zhang, W.; Lin, Y. Study on semi-finished Ship structural components assembly sequence optimization. In Proceedings of the Sixth International Conference on Natural Computation, Yantai, China, 10-12 August 2010.

8. Pamnani, R.; Jayakumar, T.; Vasudevan, M.; Sakthivel, T. Investigations on the impact toughness of HSLA steel arc welded joints. J. Manuf. Process. 2016, 21, 75-86. [CrossRef]

9. Kaya, Y.; Kahraman, N.; Durgutlu, A.; Gülenç, B. Investigation of the Microstructural, Mechanical and Corrosion Properties of Grade A Ship Steel-Duplex Stainless Steel Composites Produced via Explosive Welding. Met. Mater. Trans. A 2017, 48, 3721-3733. [CrossRef]

10. Azad, N.; Iranmanesh, M.; Darvazi, A.R. A study on the effect of welding sequence on welding distortion in ship deck structure. Ships Offshore Struct. 2019, 15, 355-367. [CrossRef]

11. Wang, J.; Yi, B.; Zhou, H. Framework of computational approach based on inherent deformation for welding buckling investigation during fabrication of lightweight ship panel. Ocean Eng. 2018, 157, 202-210. [CrossRef]

12. Huang, T.D.; Harbison, M.; Kvidahl, L. Reduction of overwelding and distortion for naval surface combatants. Part 2: Reduction of overwelding and distortion for naval surface combatants. J. Ship Prod. Design 2016, 32, 21-36. [CrossRef]

13. Park, S.-J.; Lee, H.-W. A study on the fatigue strength characteristics of ship structural steel with gusset welds. Int. J. Nav. Archit. Ocean Eng. 2012, 4, 132-140. [CrossRef]

14. Yang, Y.-P.; Castner, H.; Dull, R.; Dydo, J.; Huang, T.D.; Fanguy, D.; Dlugokecki, V.; Hepinstall, L. Complex-panel Weld Shrinkage Data Model for Neat Construction Ship Design Engineering. J. Ship Prod. Des. 2014, 30, 15-38. [CrossRef]

15. Oh, S.; Cho, B.; Kim, D.-J. Development of an Exportable Modular Building System by Integrating Quality Function Deployment and TRIZ Method. J. Asian Arch. Build. Eng. 2017, 16, 535-542. [CrossRef]

16. Lou, S.-J.; Chung, C.-C.; Dzan, W.-Y.; Tseng, K.-H.; Shih, R.-C. Effect of using TRIZ creative learning to build a pneumatic propeller ship while applying STEM knowledge. Int. J. Eng. Educ. 2013, 29, 365-379.

17. CR Classification Society. Rules for the Construction and Classification of Steel Ships, 1st ed.; CR Classification Society: Taipei, Taiwan, 2018; pp. 34-45.

18. Akay, D.; Demiray, A.; Kurt, M. Collaborative tool for solving human factors problems in the manufacturing environment: The Theory of Inventive Problem Solving Technique (TRIZ) method. Int. J. Prod. Res. 2008, 46, 2913-2925. [CrossRef]

19. Li, M.; Ming, X.; He, L.; Zheng, M.; Xu, Z. A TRIZ-based Trimming method for Patent design around. Comput. Des. 2015, 62, 20-30. [CrossRef]

20. Yamashina, H.; Ito, T.; Kawada, H. Innovative product development process by integrating QFD and TRIZ. Int. J. Prod. Res. 2002, 40, 1031-1050. [CrossRef]

21. Mann, D. Hands-On Systematic Innovation; CREAX Press: Kortrijk, Belgium, 2002.

22. Kuroshi, L.; Ölçer, A.I. A modified AD-TRIZ hybrid approach to regulation-based design and performance improvement of ballast water management system. J. Mar. Eng. Technol. 2018, 17, 147-159. [CrossRef]

23. Orloff, M.A. ABC-TRIZ: Introduction to Creative Design Thinking with Modern TRIZ Modeling; Springer: Cham, Switzerland, 2016; pp. 382-385.

24. Heo, H.; Chung, H. Stochastic assessment considering process variation for impact of welding shrinkage on cost of ship production. Int. J. Prod. Res. 2014, 52, 6076-6091. [CrossRef]

25. Kramar, V.; Dushko, V.; Rodkina, A.; Zaiets, A. Influence of Stress-corrosion Fractures on Potential of Ship-building Metals in the Sea Water. Procedia Eng. 2015, 100, 1068-1074. [CrossRef]

26. Luo, X.; Yang, Y.; Ge, Z.; Wen, X.; Guan, F. Fuzzy grey relational analysis of design factors influencing on maintainability indices. Proc. Inst. Mech. Eng. Part E J. Process. Mech. Eng. 2014, 229, 78-84. [CrossRef]

27. Romano, P.; Formentini, M.; Bandera, C.; Tomasella, M. Value analysis as a decision support tool in cruise ship design. Int. J. Prod. Res. 2010, 48, 6939-6958. [CrossRef] 